\title{
Certificação na agricultura: possibilidades de diversificação e interação para o desenvolvimento da produção regional
}

\section{Certification process in agriculture: possibilities of diversification and increments in interactions in order to promote regional production development}

\author{
Sônia Regina PAULINO* \\ Wagner Antonio JACOMETI**
}

\begin{abstract}
RESUMO
$\mathrm{O}$ artigo se dedica à análise do processo de certificação em propriedades produtoras de limão-tahiti em um dos principais pólos produtores do país, localizado no estado de São Paulo. Verifica-se a existência de um contexto marcado por dois fenômenos simultâneos. O primeiro diz respeito à expansão da lavoura de limão-tahiti e ao processo de certificação European Retailers Produce Working Group - Good Agricultural Practices (EurepGap), conduzido a partir do ano de 2002, em propriedades com essa lavoura. O segundo se refere à tendência de alteração na paisagem agrícola paulista, com a modifícação nas lavouras plantadas para atender à necessidade de aumento da produção de cana-de-açúcar e a conseqüente redução do plantio de outras lavouras. A abordagem proposta no presente artigo focaliza o entendimento do processo de certificação agrícola visto como instrumento que pode ser compatível com a diversificação produtiva e com incrementos nas interações estabelecidas entre produtores e entre estes e os demais participantes dos sistemas de produção.

Palavras-chave: certificação; EurepGap; fruticultura; frutas frescas; meio ambiente.
\end{abstract}

\footnotetext{
* Professora colaboradora do Programa de Pós-Graduação em Desenvolvimento Regional e Meio Ambiente, Centro Universitário de Araraquara (UNIARA). Pesquisadora Associada do Grupo de Estudos sobre Organização da Pesquisa e da Inovação (GEOPI) / Departamento de Política Científica e Tecnológica da Universidade Estadual de Campinas (UNICAMP). E-mail: sonia.paulino@ige.unicamp.br.

** Mestrando do Programa de Pós-Graduação em Desenvolvimento Regional e Meio Ambiente, Centro Universitário de Araraquara (UNIARA). Analista do Serviço Brasileiro de Apoio às Micro e Pequenas Empresas (SEBRAE-SP) e Gestor do Projeto Sistema Agroindustrial Integrado (SAI). E-mail: wagnerj@sp.sebrae.com.br.
} 


\begin{abstract}
The article is dedicated to the analysis of the certification process in tahiti lime farms in one of the main producing regions of the country, located in São Paulo State. We verified a context marked with two simultaneous phenomena. The first one is about the expansion of the tahiti lime production and about (EurepGap) the certification process European Retailers Produce Working Group - Agricultural Good Practices, that is managed since 2002. The second one relates to the trend of alterations the São Paulo's agricultural landscape with the modification in the crops to serve the necessity of increasing sugar cane production and the consequent reduction of the plantation of other crops. The proposed approach in the present article focuses on the understanding of the process of agricultural certification as an instrument that can be compatible with the productive diversification and increments in the interactions established between farmers and others participants of the production systems.

Key words: certification; EurepGap; fruit production; environment.
\end{abstract}

\section{Introdução}

O objetivo principal do artigo é abordar o processo de certificação enfatizando o seu papel no estabelecimento de condições para a sustentabilidade na agricultura. Busca-se analisar o papel que o processo de certificação pode desempenhar, a partir do fortalecimento da produção de lima ácida tahiti, popularmente denominada como limão-tahiti, na diversificação produtiva regional e no estímulo às interações estabelecidas entre produtores e entre estes e os demais participantes dos sistemas de produção. ${ }^{1}$

Amaro et al. (2003) apontam a relativa escassez de informações sobre a produção a industrialização e o comércio de limão no Brasil. O país é o terceiro maior produtor mundial de frutas e ocupa a primeira posição na produção de limão-tahiti (PESSOA et al., 2002), que tem se destacado como um dos frutos cítricos de maior importância comercial, com área plantada estimada superior a 40 mil hectares (AGROSOLUTION, 2005). É no estado de São Paulo que se encontra a maior parte da produção brasileira, com área superior a 30 mil hectares, com destaque para a área abrangida pelo Escritório de Desenvolvimento Rural de Catanduva, que concentra mais de 2,5 milhões de pés plantados (CATI, 2003). ${ }^{2}$

É preciso considerar a existência na região de um contexto marcado por dois fenômenos simultâneos. O primeiro diz respeito à expansão da lavoura do limãotahiti e ao processo de certificação European Retailers Produce Working Group - Good Agricultural Practices (EurepGap), conduzido a partir do ano de 2002, em propriedades com essa lavoura. O segundo se refere à tendência de alteração na paisagem agrícola paulista com a modificação nas lavouras plantadas para atender a necessidade de aumento da produção de cana-de-açúcar e a conseqüente redução do plantio de outras lavouras. As informações da safra 2004/2005 sinalizaram perspectivas de acréscimos da produção agrícola da cana-de-açúcar destinada à indústria (BAPTTISTELLA et al., 2005). Estima-se a necessidade de aproximadamente 50 novas unidades, com capacidade de moagem unitária de três milhões de toneladas por safra. Metade dessas plantas industriais deve ser instalada no noroeste e oeste paulistas, ocupando áreas de pastagem, grãos e laranja (SOUZA, 2005).

1 A denominação limão é comumente usada para indicar frutas cítricas de sucos ácidos e inclui os limões verdadeiros (Citrus limon) como Siciliano, Eureca, Vilafranca e Lisboa, e as limas ácidas conhecidas como limão-tahiti (Citrus latifolia) e limão galego (Citrus aurantifolia). Por esse motivo, as estatísticas de produção, comércio, processamento industrial e preços divulgados pela Food and Agriculture Organization (FAO) não se referem separadamente a cada um deles. Apenas em casos isolados aparecem citações fragmentadas separando as limas ácidas (lime), cuja literatura sobre a cultura é escassa, dos limões verdadeiros (lemon). O mesmo ocorre no Brasil com os dados do Instituto Brasileiro de Geografia e Estatística (IBGE) e do Instituto de Economia Agrícola (IEA/SAA-SP) (AMARO et al., 2003).

2 O Escritório de Desenvolvimento Rural (EDR) de Catanduva é uma Unidade Administrativa da Coordenadoria de Assistência Técnica Integral (CATI) da Secretaria da Agricultura e Abastecimento do Estado de São Paulo que substituiu as Divisões Regionais Agrícolas (DIRAS) e Delegacias Agrícolas. Ao todo são quarenta Escritórios Regionais Agrícolas - CATIs Regionais ou EDRs distribuídos por todo o estado de São Paulo. 
O EurepGap é um esquema de referência de boas práticas agrícolas, com participação voluntária, e que visa atender o interesse do consumidor em termos de segurança alimentar, bem-estar animal, proteção ambiental e saúde, segurança e bem-estar do trabalhador. EUREP refere-se a European Retailers Produce Working Group, que definiu um protocolo de boas práticas agrícolas, ou Good Agricultural Practices - GAP, que devem ser seguidas pelos produtores para a obtenção e a manutenção da certificação. A certificação pode ser requerida pelos produtores individualmente ou em grupo (EUREPGAP, 2004).

É focalizado o processo de implantação da certificação EurepGap em propriedades produtoras de limão-tahiti no EDR de Catanduva, um dos principais pólos produtores dessa lavoura no país. Procedeu-se à realização de pesquisa e organização de dados primários obtidos na empresa responsável pelo acompanhamento da implantação dos procedimentos requeridos pelo protocolo de certificação. Foram obtidas informações sobre um grupo de 50 propriedades distribuídas em cinco municípios.

A estrutura do trabalho apresenta cinco itens, contando com esta introdução. O segundo item se dedica à literatura acerca da certificação, com o intuito de destacar duas abordagens que se sobressaem nas análises que auxiliam no entendimento do papel da certificação na agricultura: certificação enquanto fator de aumento da competitividade e como instrumento que deve ser analisado levando em conta seus possíveis desdobramentos sobre as condições de sustentabilidade dos sistemas de produção nos quais incide. O terceiro item sintetiza o cenário que se coloca em termos da evolução da produção e comercialização do limão-tahiti. $\mathrm{O}$ quarto item é baseado na pesquisa empírica sobre um grupo de propriedades certificadas do EDR de Catanduva. E no quinto item são apresentadas as conclusões.

\section{Certificação: fator de competitividade e fator de sustentabilidade}

O tema da certificação tem sido crescentemente enfatizado nos estudos acerca dos sistemas agroindustriais.

Em um cenário de aumento do comércio internacional, é mais fácil dimensionar o tamanho das barreiras tarifárias impostas aos países exportadores, sendo que o mesmo não ocorre com as barreiras não tarifárias abrindo espaço para a colocação de restrições ambientais, sociais, sanitárias e padrões de qualidade distintos. Identifica-se a criação de um novo padrão de concorrência no qual a obtenção de custos baixos é necessária, mas deixa de ser condição suficiente. Nesse contexto, a certificação é vista como atividade importante, tendo como objetivo principal proporcionar ao comprador ou usuário do produto a garantia de conformidade às normas ou às especificações técnicas estabelecidas. A questão da certificação pode ser vista sob dois enfoques: atendimento às exigências internacionais (barreira técnicas) e ao mercado interno (diferenciação do produto com a sua conseqüente valorização). Assim, atributos de qualidade dos produtos ligados à segurança alimentar, boas práticas agrícolas e biotecnologia são temas presentes no setor agroindustrial, mobilizando decisões do setor privado e apresentando impactos imediatos no desenho de políticas públicas para o setor agrícola/agroindustrial (CONCEIÇÃO; MENDONÇA DE BARROS, 2005). O aumento da competitividade, como resultado da elevação da produtividade e da qualidade, com menores custos unitários de produção, aponta claramente para as diretrizes a serem perseguidas (CASER; AMARO, 2004).

Um sistema de certificação garante que um produto atenda a especificações predeterminadas (NASSAR, 2003). Zylbersztajn (2003) aponta que o conceito de gestão de sistemas agroindustriais (SAGs) tem levado empresários, acadêmicos e gestores públicos a se defrontarem com uma nova realidade, na qual o foco predominante vem sendo repensado para englobar a adição de valor ao longo dos canais de distribuição. Nesse sentido, a temática da qualidade aparece como prioritária, explicitando novos papéis esperados para os atores atuantes nos sistemas agroindustriais, ao lidar com a agricultura e as atividades a ela ligadas. Certificação, padronização e rastreabilidade constituem temas centrais para a obtenção de avanços na direção de SAGs eficientes e competitivos e colocam a necessidade de instrumentalização do Estado e do setor privado para lidar com esses temas. A partir dessa realidade, a adoção de métodos de gestão de SAG requer uma estrutura de pesquisa, de informações, de ensino e de educação continuada e de capacidade de monitoramento aprimorada, por parte do Estado. Nunca foi importante como hoje o aprimoramento da capacidade de desenvolver conhecimento (não apenas de gerar informação) e permitir a fluência dos agentes produtivos.

No mundo atual, processos de certificação são discutidos não apenas por técnicos, burocratas e cientistas, mas também pelos mais diversos setores da sociedade, que incluem consumidores, varejistas e organizações não governamentais. A busca pela qualidade e pela certificação 
de produtos agropecuários está baseada em acontecimentos intrínsecos à sociedade brasileira bem como às exigências dos mercados externos, principalmente o europeu e o norteamericano. Os ganhos advindos da qualidade se refletirão no preço final do produto, pois o maior aproveitamento da matéria-prima (produto agropecuário) implica menores custos para a sua seleção e separação e maior vida útil do produto na prateleira. A viabilização dessas expectativas requer investimento em qualidade, cujo padrão nacional, em comparação com aqueles adotados em outros países, não permite que nossos produtos sejam competitivos (PESSOA et al., 2002).

Há que se levar em conta também que, na prática, a evolução do sistema de certificação encontra-se ainda em seu estágio inicial. Considerando a experiência européia, a título de exemplo, a sua implantação está constituindo um problema crucial (SPILLER et al., 2004, apud DORR; MARQUES, 2005).

Em um enfoque mais amplo, não restrito ao foco na certificação como fator de competitividade, a certificação tem estimulado o debate sobre sustentabilidade na agricultura. Canuto (2003) e Altieri e Nicholls (2003) apontam que a agricultura ecológica de mercado, por estar condicionada ao cumprimento de normas técnicas, a ritos de certificação, tende a provocar um processo de exclusão dos agricultores mais pobres ou pode levar a situações em que os produtores não são os que mais ganham no processo.

Kitamura (2003) afirma que dois caminhos se complementam em direção a uma agricultura sustentável. Um deles corresponde à introdução de inovações na agricultura intensiva, com as questões ambiental e a de saúde se somando à meta de aumento de produção e produtividade. O outro caminho é aquele que aponta para o crescimento da agricultura orgânica e dos sistemas agroecológicos. O autor prossegue apontando que a nova configuração da agricultura intensiva no Brasil, com características de permanência no mercado futuro, passa a incorporar, de forma voluntária, também em resposta às exigências crescentes do mercado internacional, a certificação de qualidade do produto e ambiental no processo produtivo e, com isso, os instrumentos de avaliação e de monitoramento dessa qualidade visando melhorias contínuas.

A produção de orgânicos, em consonância com a inserção dos produtos orgânicos no hábito alimentar dos consumidores, vem permitindo a criação de nichos de mercado. Um produto orgânico é comprovado por uma certificação que atesta para o comprador que ele está consumindo um bem cuja produção atendeu todo um conjunto de processos que garantem a produção nos moldes da agricultura orgânica. Estudo sobre a variedade da oferta de orgânicos no país aponta as frutas com a maior participação entre as categorias de produtos que vem sendo priorizados. Assim, considerando uma amostra de 1.565 itens levantados na produção orgânica no Brasil, 34\% são representados por frutas, $26 \%$ por produtos industrializados, $17 \%$ por grãos, $12 \%$ por outros e $6 \%$ por legumes (GRAZIANO et al., 2007).

Assad e Almeida (2004) apontam que os consumidores de países industrializados exigem uma variedade cada vez maior de critérios de qualidade antes de comprar alimentos, com implicações mais drásticas na área da produção agrícola, especialmente entre pequenos e médios produtores que não participam de organizações e/ou são pouco integrados em circuitos de comercialização.

\section{Breve panorama da fruticultura brasileira: limão-tahiti}

O Brasil ocupa o terceiro lugar na produção mundial de frutas, com a quantidade de 38.125 .000 toneladas, sendo um grande produtor de laranja, banana, coco e mamão. A China é o maior produtor mundial de frutas, com quantidade de 133.077.000 toneladas e destacandose como um grande produtor mundial de melancia, maçã, melão e pêra. A Índia é o segundo produtor mundial, com a quantidade de 58.970 .000 de toneladas, sendo também um grande produtor de banana, manga e coco (OLIVEIRA e MANICA, 2003).

Para Chabaribery e Alves (2001), a fruticultura no Brasil vem obtendo cada vez mais atenção das instituições de pesquisa, em virtude da expectativa de que a racionalização e o aumento de competitividade na produção e distribuição, inclusive para exportação, gerem maior renda e estabilizem o emprego de parcela da população rural. É uma atividade que requer muitos cuidados com a qualidade, e a pequena agricultura familiar pode ser apontada como privilegiada para atender a essa produção com qualidade: áreas pequenas que facilitam o monitoramento de pragas, doenças e o trabalho realizado por empregados contratados; interesse no negócio; membros da família que possam se dedicar em tempo parcial à atividade; entre outro motivos.

Restringindo-se à produção de limão e de lima ácida, e de acordo com dados da FAO relativos a 2001, nas duas últimas décadas a produção mundial aumentou $66 \%$. Desse 
total, aproximadamente $75 \%$ são produzidos em países do Hemisfério Norte (em boa parte na região do Mediterrâneo) e o restante no Hemisfério Sul. Já as exportações avançaram em 55\%, sendo que, em termos relativos, a maior contribuição ficou por conta dos países do Hemisfério Sul, para os quais as vendas externas foram quadruplicadas (de $81 \mathrm{mil}$ para 331 mil toneladas) (AMARO et al., 2003).

Para o caso brasileiro, a produção com caráter comercial, para 2000, é estimada em aproximadamente 25 milhões de caixas de 40,8kg. A área colhida aumentou na década de 1990, atingindo cerca de 50 mil hectares. Dados mais recentes, do período de 1989 a 2002, confirmam o destaque para o estado de São Paulo, onde houve importante aumento da produção, com ampliação do número de árvores plantadas e da produtividade (AMARO et al., 2003). Com base em uma série de estimativas para o período 1965-2004, na cultura de limão (verdadeiro e de limas ácida tahiti e galego), o plantio aumentou duas vezes entre os qüinqüênios 1970-1975 e 2000-2004, e a área com pés em produção evoluiu 2,4 vezes. Nesses 40 anos, a incidência de cancrose do limão dizimou a cultura do limão galego e intensificou o plantio do limão-tahiti, que, além de ganhar a preferência dos consumidores brasileiros, passou a conquistar cada vez mais o mercado internacional, graças, em grande parte, aos avanços tecnológicos e à prática da irrigação, de modo a propiciar a colheita de frutos com excelente qualidade e aparência (CASER; AMARO, 2004). Então, a produção do limão-tahiti ocorre em maior escala e, secundariamente, se dá a produção dos limões siciliano, galego e rosa ou cravo. Suscetíveis ao cancro cítrico, os limões do grupo com sementes foram perdendo área desde os anos 60 (CHABARIBERY; ALVES, 2001). O limão-tahiti constitui um fruto de origem tropical de exploração econômica relativamente recente (CATI, 2005). No período de 1990 a 2001, as exportações de limão-tahiti passaram de 2,7 mil toneladas para 14,8 mil toneladas, com evolução positiva também para o preço (AMARO et al., 2003).

\section{Certificação EurepGap em propriedades produtoras de limão-tahiti no EDR de Catanduva}

Dados do Instituto de Economia Agrícola (IEA, 2004) ilustram o quadro atual para a produção de cana-deaçúcar, laranja e limão em São Paulo. A produção de cana para indústria, em 2004, foi de 241,7 milhões de toneladas, revelando um aumento de $27,68 \%$ em relação à produção de 2000, que foi de 189,3 milhões de toneladas. A região estudada, Catanduva, representou $4,95 \%$ da produção de cana para a indústria no estado de São Paulo, com uma produção de 11,9 milhões de toneladas e área para corte de 150.183 hectares.

Ao mesmo tempo, as estimativas para a expansão do setor sucroalcooleiro, divulgadas pela União da Agroindústria Canavieira de São Paulo (UNICA), apontam que a produção brasileira anual de etanol deverá saltar de 15,2 bilhões de litros para 26,4 bilhões em 2010. Para atender a essa demanda da indústria em expansão, a área plantada de cana-de-açúcar, de 5,5 milhões de hectares, terá de incorporar mais 2 milhões de hectares. Estima-se ainda a colocação em operação de um importante número de usinas nos estados de São Paulo, Goiás e Minas Gerais, para abastecer os mercados interno e externo (IZIQUE, 2005).

Quanto à cultura de laranja, a produção no estado de São Paulo, em 2004, foi de 360,7 milhões de caixas de 40,8 $\mathrm{kg}$, registrando aumento de $1,23 \%$ em relação à produção de 2000, que foi de 356,3 milhões de caixas. Apesar deste pequeno aumento, os pés de laranja em produção no estado de São Paulo diminuíram de 195,2 milhões de pés para 188,1 milhões, registrando uma redução de 3,64\%. Segundo Pessoa et al. (2002), a crise no setor da laranja fez progredir o setor das limas ácidas brasileiras (galego e tahiti) por se tratar de fruteiras mais resistentes à maioria das doenças que atingem os produtos cítricos. Além disso, o mercado europeu tem se mostrado promissor para o limão-tahiti.

A produção de limão no estado de São Paulo, em 2004, foi de 23,7 milhões de caixas de $40,8 \mathrm{~kg}$, o que representou um aumento de $13,40 \%$ em relação à produção de 2000, que foi de 20,9 milhões de caixas. O que também aumentou de 2000 para 2004 foi a produtividade. Enquanto, em 2000, a produtividade foi de 2,84 caixas por pé de limão, em 2004 a produtividade foi de 3,09 caixas. Para Amaro et al. (2003), o aumento da produtividade pode ser explicado pelo adensamento do plantio nos pomares e por melhores tratos culturais, incluindo-se mudas com maior potencial genético.

Assim, a expansão da lavoura do limão-tahiti na região estudada, ocorrida a partir de 1999, está ligada às melhores perspectivas do produtor quanto aos preços de venda e às alternativas de comercialização nos mercados interno e externo (preço maior e menor concentração de compradores, em relação à lavoura da laranja). O plantio do limão é apontado também como alternativa ao aumento da área plantada de cana-de-açúcar na propriedade. 
Os 18 municípios que compõem o Escritório de Desenvolvimento Rural (EDR) de Catanduva são responsáveis por $40,86 \%$ da produção de limão no estado de São Paulo, com 9.705.965 caixas de 40,8 kg produzidas em 3.125 propriedades. Em número de pés de limão em produção, a região responde por $34,83 \%$ do total no estado de São Paulo. Na mesma região foram plantados, em 2004, 371.725 novos pés de limão, o que representou $37,42 \%$ da incorporação de pés da fruteira. Os maiores municípios produtores de limão no EDR de Catanduva são Itajobi, Urupês, Irapuã e Marapoama.

A amostra considerada no presente estudo se refere a um grupo de 50 propriedades certificadas com a participação de pequenos (44\%), médios (52\%) e grandes (4\%) produtores, segundo o número de pés de limão plantados. Para classificar a capacidade de produção nas diferentes propriedades, a empresa responsável pelo processo de implantação do protocolo de certificação considera a quantidade de pés de limão plantados de acordo com o seguinte critério: de 200 a 1.000 pés é considerado pequeno produtor, de 1.001 a 5.000 pés é considerado como médio produtor e a partir de 5.001 pés é considerado como grande produtor.

No presente artigo, a análise dos dados das informações assim obtidos procura enfatizar possibilidades e limites do processo de certificação no tocante à compatibilidade com o desenvolvimento da produção agrícola na região estudada, baseando-se na diversificação produtiva e na interação entre produtores e destes com os demais participantes dos sistemas de produção, em torno de objetivos comuns que visam a manutenção da certificação. Procurase destacar esses aspectos na apreensão do sucesso dos processos de certificação em termos dos desdobramentos sobre o desenvolvimento regional.

Os Pontos de Controle e Critérios de Cumprimento (PCCC) têm que ser considerados pelos produtores requerentes, que são auditados para verificar o seu cumprimento. Os PCCC estão divididos em 14 seções e lista as obrigações maiores (47 Pontos de Controle), as obrigações menores (98 Pontos de Controle) e as recomendações (65 Pontos de Controle), num total de 210 Pontos de Controle, ilustrados no quadro a seguir.

\begin{tabular}{|c|c|c|c|}
\hline SEÇÃO & PONTOS DE CONTROLE E CRITÉRIOS DE CUMPRIMENTO & N. PCCC & TOTAL $\%$ \\
\hline 2 & Manutenção de Registros e Auto-Avaliação Interna & 4 & 1,90 \\
\hline 3 & Variedades e Porta-Enxertos & 11 & 5,24 \\
\hline 4 & História e Gestão da Unidade de Produção & 5 & 2,38 \\
\hline 5 & Gestão do Solo e dos Substratos & 10 & 4,76 \\
\hline 6 & Fertilização & 21 & 10,00 \\
\hline 7 & Rega/Fertirrigação & 16 & 7,62 \\
\hline 8 & Proteção de Culturas & 62 & 29,52 \\
\hline 9 & Colheita & 9 & 4,29 \\
\hline 10 & Acondicionamento do Produto & 30 & 14,29 \\
\hline 11 & Gestão de Resíduos e Poluentes, Lavagem e Reutilização & 6 & 2,86 \\
\hline 12 & Saúde, Segurança e Bem-Estar dos Trabalhadores & 24 & 11,43 \\
\hline 13 & Questões Ambientais & 9 & 4,29 \\
\hline 14 & Reclamações & 2 & 0,95 \\
\hline \multicolumn{2}{|l|}{ Total } & 210 & 100,00 \\
\hline
\end{tabular}

Fonte: Elaborado pelos autores a partir de EurepGap - Regulamento Geral de Frutas e Legumes (2004).

QUADRO - PONTOS DE CONTROLE E CRITÉRIOS DE CUMPRIMENTO - PCCC

A análise dos dados da avaliação das propriedades para classificação, no início do processo de certificação, segundo nível de atendimento aos requerimentos do pro- tocolo, aponta para desdobramentos que incidem sobre o produtor e cuja apreensão ocorre em dois níveis de análise: $\mathrm{o}$ interno e o externo à propriedade. 


\section{Alterações no sistema produtivo}

Durante o processo de certificação EurepGap, as propriedades são inicialmente enquadradas segundo níveis de atendimento às exigências dos Pontos de Controle e Critérios de Cumprimento-PCCC. As propriedades que atingem o nível 1 são aquelas com maior nível de enquadramento nas referidas exigências; as de nível 2 possuem nível de atendimento intermediário; e as de nível 3 são aquelas que não atendem ou atendem muito pouco às exigências do protocolo.

Para o grupo de produtores aqui considerado, $62 \%$ foram enquadrados no nível 3, colocando a necessidade de realizar grandes alterações para classificação futura no nível 1. O enquadramento no nível 3 é maior entre os pequenos produtores, $77 \%$, ficando em $54 \%$ entre os médios.

O detalhamento desse quadro aponta para a existência de vários PCCC avaliados como pontos críticos, isto é, aqueles em que foram identificados importantes requerimentos em termos de introdução de modificações no sistema produtivo, uma vez que as respectivas propriedades foram classificadas inicialmente nos níveis 2 ou 3. Os PCCC avaliados como críticos quanto ao nível de atendimento na fase inicial do processo de certificação são apresentados a seguir.

- Fertilização - Foi analisada como um ponto crítico, sendo necessárias grandes adequações para atender às exigências do protocolo. Como ponto crítico dessa seção, destaca-se a subseção registro de aplicações, devido à grande dificuldade colocada pelos produtores para efetuar os registros das aplicações dos fertilizantes orgânicos ou inorgânicos, como datas, identificação do produto, métodos e nome do operador.

- $\quad$ Proteção de Culturas - Também foi considerado um ponto crítico, sendo necessárias grandes adequações para que venha a ser atingido o nível 1 de atendimento dos PCCC. Na subseção registro de aplicação de produtos fitofarmacêuticos, foi identificada grande dificuldade em registrar informações: local, dia, nome comercial, substâncias ativas, justificativas para sua utilização, intervalos de segurança etc.

- Gestão de Resíduos e Poluentes, Reciclagem e Reutilização - Levando em conta a subseção identificação dos resíduos e poluentes, foi identificada a necessidade de proceder à destinação final adequada das embalagens vazias de agrotóxicos e fertilizantes, consideradas no protocolo como fontes de poluição, sendo necessárias adequações para atendimento às exigências do cumprimento do PCCC.

- Saúde, Segurança e Bem-Estar dos Trabalhadores - Verificou-se a necessidade de assegurar a utilização de equipamentos de proteção individual (EPI) adequados para aplicação dos produtos fitofarmacêuticos.

- Questões Ambientais - Observou-se a necessidade de promover avanços na explicitação, pelo produtor, da sua compreensão e avaliação dos impactos que sua atividade pode causar ao meio ambiente.

Foram identificados os principais pontos, em termos da necessidade de introdução de alterações no sistema produtivo, a considerar para a obtenção, pelos produtores, de vantagens atreladas ao fortalecimento da lavoura de limãotahiti a partir da adesão ao protocolo EurepGap.

\section{Interações externas à propriedade}

Uma segunda questão a ser enfatizada extrapola as modificações no interior da propriedade e diz respeito às interações estabelecidas entre produtores e outros participantes dos sistemas de produção.

A interação tem se mostrado muito importante entre grupos já certificados e aqueles em fase de certificação. $\mathrm{O}$ objetivo é explicitar quais são as reais exigências colocadas para o produtor quando da adesão ao protocolo. Trata-se de depoimentos de produtores, relatando vantagens e desvantagens e também as dificuldades encontradas durante o processo de certificação.

A adesão ao processo de certificação tem sido ainda acompanhada do recebimento de assistência técnica especializada e permanente possibilitado pela empresa exportadora, com a finalidade de propiciar o acompanhamento constante do produtor quanto ao cumprimento de maneira adequada dos PCCC. Um outro tipo de interação identificado está ligado ao oferecimento, também promovido pela empresa que realiza a classificação e embalagem do produto (packing house), de cursos de capacitação que foquem a adoção de boas práticas agrícolas.

Essa situação suscita o levantamento da questão acerca da existência de espaços a serem ocupados pela 
assistência técnica pública no que diz respeito ao avanço da sua inserção em processos de certificação, de modo a fortalecer e induzir o desenvolvimento da produção regional.

Ainda com relação à packing house, os investimentos que viabilizaram a certificação foram assumidos por essa empresa, motivada pelas exigências do mercado externo, que passou a exigir a certificação também da propriedade produtora de limão. A opção pela certificação em grupo permitiu a redução dos custos envolvidos no processo, considerado elevado pela maioria dos produtores. Apesar de receber um preço maior pelo limão e de contar, num contexto marcado por grande demanda externa, com a garantia de ter toda a produção certificada destinada à exportação, os produtores passaram a ter a packing house, detentora do certificado, como única compradora para o seu produto.

A experiência de estabelecimento de monopsônio tem sido acompanhada pela busca de viabilização de formas alternativas de relação produtor-comprador(es) que possibilitem processos de certificação de propriedades de limão-tahiti, nos quais a organização certificadora credenciada não esteja atrelada à packing house, que seria substituída, por exemplo, por associações de produtores e organizações não governamentais. Nesse sentido, organizações privadas - Associação Brasileira dos Produtores e Exportadores de Limão (ABPEL), Instituto Brasileiro de Frutas (IBRAF) e Serviço Brasileiro de Apoio às Micro e Pequenas Empresas (SEBRAE) - estão firmando parcerias

\section{Referências}

AGROSOLUTION. Disponível em: < http://www.agrosolution. com.br.>Acesso em: 16/11/2005.

ALTIERI, Miguel A.; NICHOLLS, Clara, I. Agroecologia: resgatando a agricultura orgânica a partir de um modelo industrial de produção e distribuição. Ciência \& Ambiente, Universidade Federal de Santa Maria, n. 27 p. 141-152, jul./ dez. 2003.

AMARO, Antonio A.; CASER, Denise V.; DE NEGRI, José D. Tendências na Produção e Comércio de Limão. In: Informações Econômicas, São Paulo, v. 33. n. 4, p. 37-47, abr. 2003.

ASSAD, Maria L. L.; ALMEIDA, Jalcione. Agricultura e sustentabilidade: contexto, desafios e cenários. Ciência \& Ambiente, Universidade Federal de Santa Maria, n. 29 p. 15-30, jul./ dez. 2004. com o objetivo principal de arregimentar e fomentar ações ligadas à certificação, de maneira a fortalecer a cadeia produtiva do limão-tahiti na região.

\section{Conclusão}

O processo de certificação tem se colocado como uma vantagem para o produtor em busca da permanência no mercado de limão e do fortalecimento dessa lavoura na região. A produção de limão-tahiti tem se destacado em termos de rentabilidade. Assim, é associada à viabilização de uma produção rentável em pequenas áreas, colocando-se como alternativa à produção da cana-de-açúcar. E também é apontada como uma lavoura com custos menores para o controle de pragas e doenças e com a possibilidade de ser exportada in natura, constituindo alternativa à produção de laranja.

A adesão ao protocolo EurepGap introduziu exigências cujo atendimento viabilizou o incremento de relações de interação entre os produtores e também destes com outros participantes dos sistemas de produção do limão-tahiti (compradores e assistência técnica). Essas interações são fortemente marcadas pela iniciativa e pela orientação da empresa que responde pela classificação e pela embalagem do produto para exportação (packing house), situação que explicita a necessidade de fortalecer e induzir iniciativas que permitam o estabelecimento de interações diferenciadas e compatíveis com a maior participação dos produtores na condução e orientação do processo de certificação.

BAPTTISTELLA, Celma, S. L. et al. População trabalhadora no rural paulista em 2004. Disponível em: <http://www.iea. sp.gov.br> Acesso em: 21/08/2005.

CANUTO, João Carlos. A pesquisa e os desafios da transição agroecológica. Ciência \& Ambiente, Universidade Federal de Santa Maria, n. 27 p.133-140, jul./ dez. 2003.

CASER, Denise V.; AMARO, Antonio A. Evolução da produtividade na citricultura paulista. Informações Econômicas, São Paulo, v. 34, n. 10, p. 7-12, out. 2004.

CHABARIBERY, Denyse; ALVES, Humberto Sebastião. Produção e comercialização de limão, mamão, maracujá e melancia em São Paulo. Informações Econômicas, São Paulo, v. 31, n. 8, ago. 2001. 
COORDENADORIA DE ASSISTÊNCIA TÉCNICA INTEGRAL. Levantamento Censitário de Unidades de Produção Agrícola do Estado de São Paulo. São Paulo: CATI/ SAA, 2003. (não publicado).

COORDENADORIA DE ASSISTÊNCIA TÉCNICA INTEGRAL (CATI) Disponível em: < http://www.cati.gov. br> Acesso em: 08/06/2005.

CONCEIÇÃO, Júnia C. P. R.; MENDONÇA DE BARROS, Alexandre L. Certificação e rastreabilidade no agronegócio: instrumentos cada vez mais necessários. Instituto de Pesquisa Econômica Aplicada, Texto para Discussão n. 1122. Brasília, out. de 2005. 47 p.

DORR, Andréa C.; MARQUES, Pedro V. Estudo preliminar sobre rastreabilidade e certificação da maçã gaúcha exportada para a União Européia. In: XLIII Congresso da Sociedade Brasileira de Economia e Sociologia Rural, 43., Ribeirão Preto, 24 a 27 de jul. de 2005. 12 p.

EUREPGAP. Regulamento geral de frutas e legumes. 2004, 64 p.

GRAZIANO, Graziela O.; SPERS, Eduardo E.; PIZZINATTO, Nadia K.; GIULIANI, Antonio C.; CORRÊA, Dalila, A. Estratégia de Desenvolvimento de Produtos no Agronegócio: Um estudo no setor de produtos orgânicos. In: Congresso da Sociedade Brasileira de Economia, Administração e Sociologia Rural, 45., Londrina, 22 a 25 jul. 2007, 20 p.

INSTITUTO DE ECONOMIA AGRÍCOLA (IEA). 2004. Disponível em: <http://www.iea.sp.gov.br $>$ Acesso em: 21/08/2005.
IZIQUE, Claudia. Movido a álcool: país deverá produzir mais de 26 bilhões de litros de etanol em 2010 e o número de novas usinas não pára de crescer em São Paulo, Goiás e Minas Gerais. Indústria Brasileira, Brasilia, Confederação Nacional da Indústria (CNI), abr. de 2005, p. 34-37. Disponível em: <http://www.cni. org.br> Acesso em: 31/01/2006.

KITAMURA, Paulo C. Agricultura sustentável no Brasil: avanços e perspectivas. Ciência \& Ambiente, Universidade Federal de Santa Maria, n. 27, p. 7-28, jul./ dez. 2003.

NASSAR, André M. Certificação no Agribusiness. In: ZYLBERSZTAJN, Décio; SCARE, Roberto, F. (Org.). Gestão da qualidade no agribusiness: estudos e casos. São Paulo: Atlas, 2003. p. 30-46.

OLIVEIRA, Mauro E.; MANICA, I. Principais países produtores de frutas no ano de 2002. Informativo IBRAF, n. 20, ano 4 abr. 2003. Disponível em: <http://www.ibraf.org.br/x-no/ iol/a4n20/inf20mail.htm> Acesso em: 31/01/2006.

PESSOA, Maria Conceição P. Y.; SILVA, Aderaldo. S.; CAMARGO, Silas, P. Qualidade e certificação de produtos agropecuários. Texto para Discussão 14, Embrapa Informação Tecnológica, Brasília, 2002. 191 p.

SOUZA, Carlos E. O domínio da cana. Diário da Região, São José do Rio Preto, 15 out. 2005.

ZYLBERSZTAJN, Décio. Gestão da qualidade no agribusiness. In: ZYLBERSZTAJN, Décio; SCARE, Roberto, F. (org.). Gestão da qualidade no agribusiness: estudos e casos, São Paulo: Atlas, 2003. p. 15-17. 